\title{
Techno-economic analysis of levoglucosan production via fast pyrolysis of cotton straw in China
}

Junqi Wang ${ }^{1}$, Ajay Shah ${ }^{1 *}$

\section{INTRODUCTION}

- China, one of the largest agricultural countries in the world, is rich in agricultural biomass resources. The yield of cotton straw is projected to increase by $7.2 \%$ annually ${ }^{1}$. Cotton straw is usually combusted directly in the countryside, which largely pollutes the environment.

Cotton straw is a suitable resource for the production of biooil via fast pyrolysis, which can be further upgraded to a high value product, levoglucosan, through extraction

- Levoglucosan can be used for several applications, such as, pesticides, growth regulators, macrolide antibiotics ${ }^{3}$. Levoglucosan can be obtained via fast pyrolysis and AIM

Investigate the techno-economic feasibility of the production of levoglucosan through fast pyrolysis of cotton straw in China.

\section{METHODS}

Software: SuperPro Designer v 9.5

System boundary: Depicted in Figure 1

Annual processing capacity: 200,000 ton of cotton straw Data collection:

- Bio-oil and levoglucosan yield data

- Process parameters: such as temperature, pressure and time

- Facilities and equipment data

Collected from lab experiments, literature ${ }^{1}$ and

Analysis:

- Material balance and energy requirements

- Operating cost

Financial analysis: Gross margin (GM), return on investment (ROI), internal rate of return (IRR), net present value (NPV) and payback time (PBT) for different levoglucosan price conditions (see Table 1 for details).

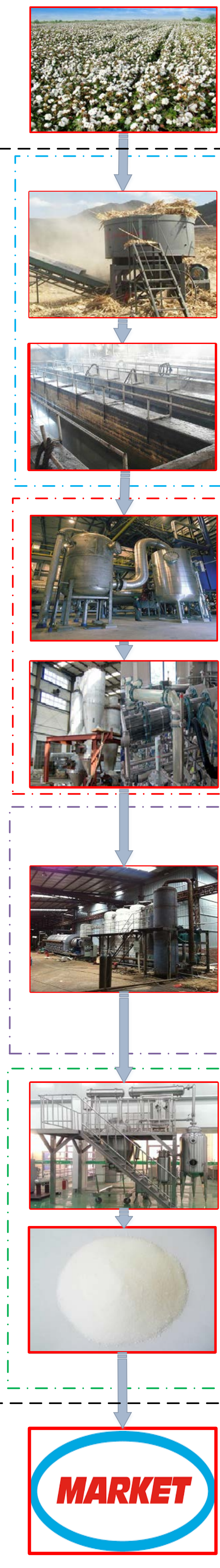

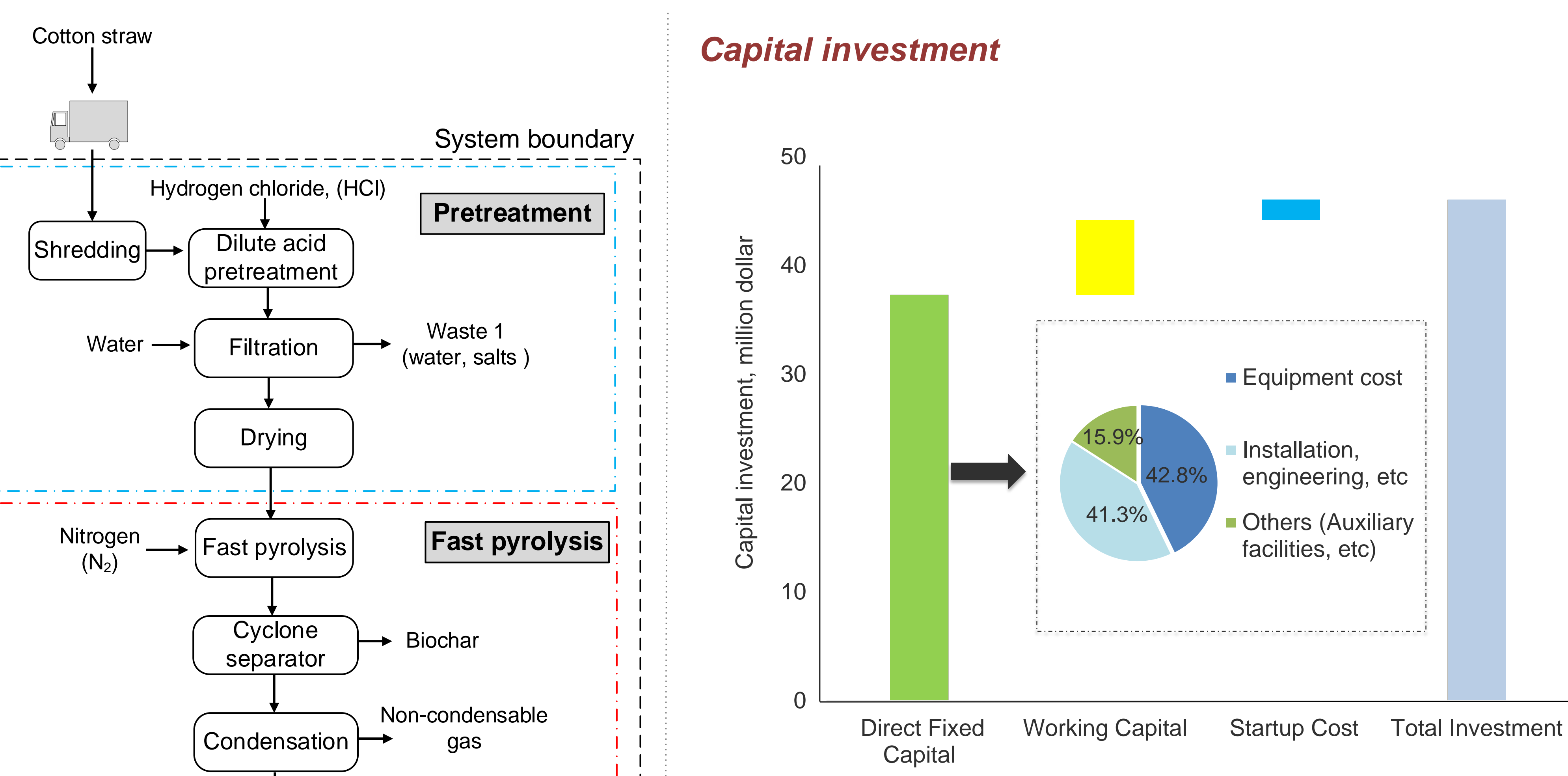

Figure 3. Capital investment

Total capital investment for levoglucosan production was estimated to be around $\$ 46$ million.

nt cost, installation engineerng cost) was about $81 \%$ of the total capita

for acting around $41 \%$ of the direct fixed capital cost required for installation, buildings materials, engineering, and construction.

Operating cost

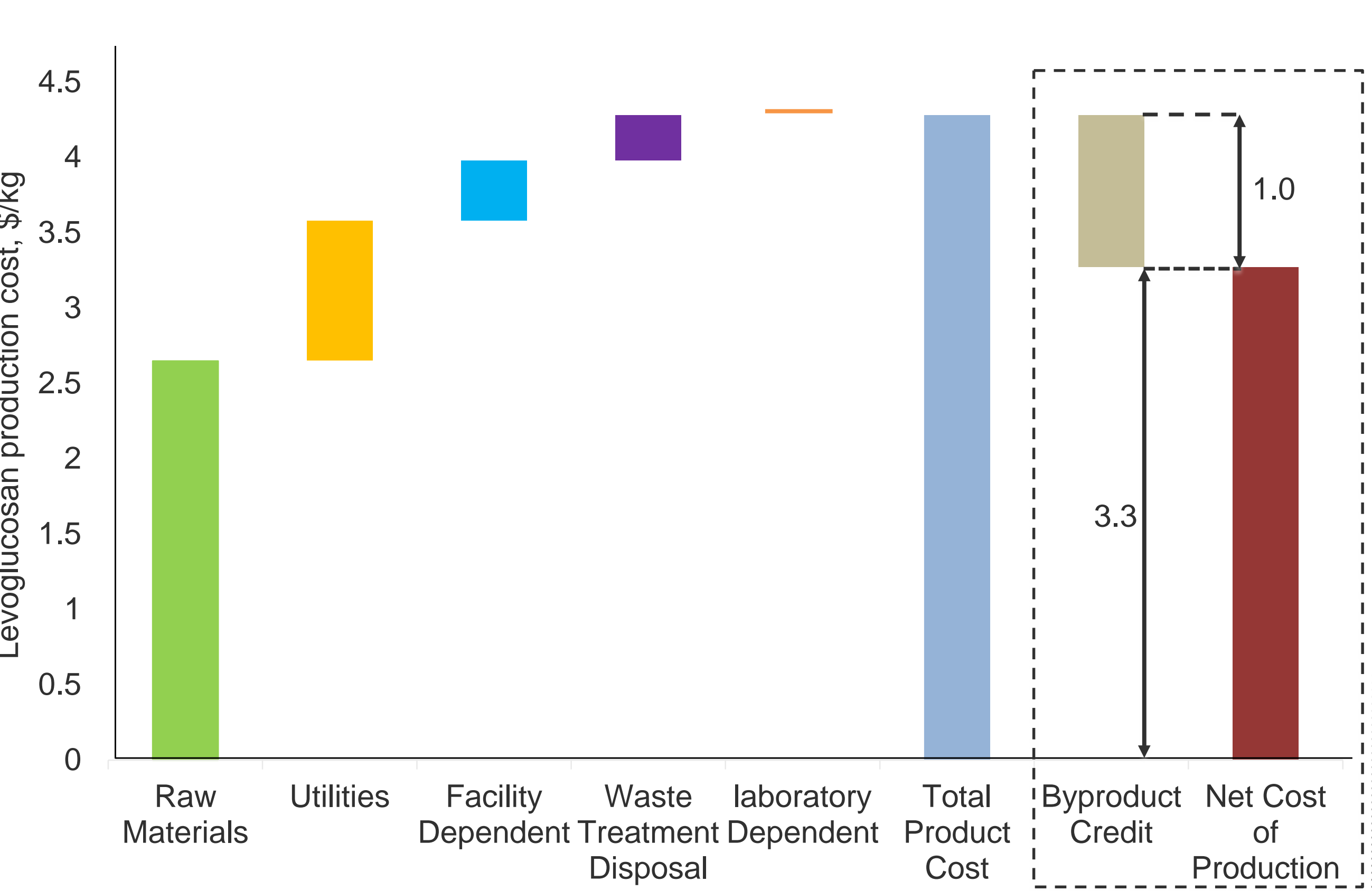

Figure 4. Levoglucosan production cost

- Annual operating cost for levoglucosan production was estimated to be $\$ 77.1$ million. The gross cost of

levoglucosalus about $\$ 4.3 / k g$.

- contributor to the annual other input materials $\left(\mathrm{Ca}(\mathrm{OH})_{2}, \mathrm{HCl}\right)$.

This plant generated about $\$ 17.9$ million annual credits from byproducts, mainly biochar and non-condensable gases. Considering byproduct credits, the net levoglucosan cost was estimated to be $\$ 3.3 / \mathrm{kg}$.
Sensitivity analysis

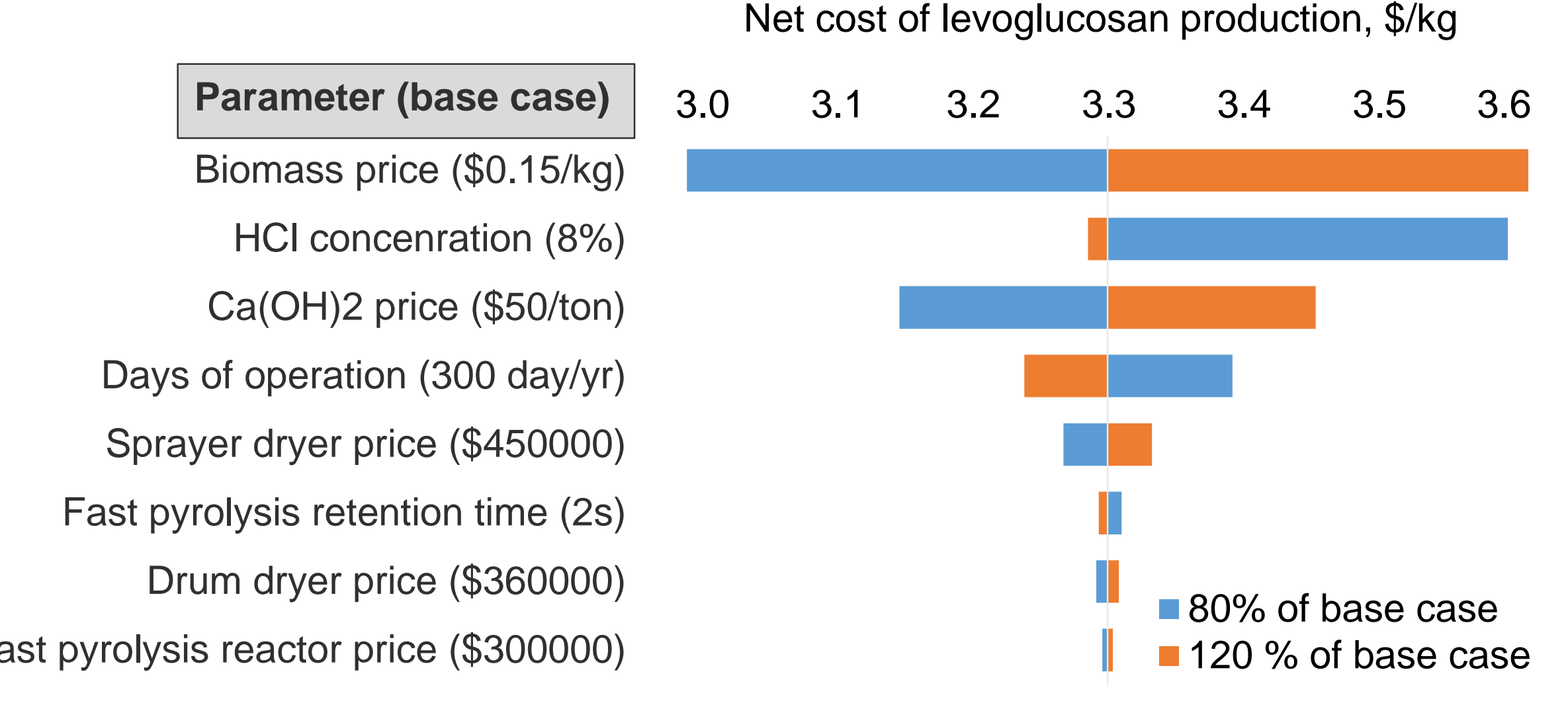

Figure 5. Sensitivity analysis

The sensitivity analysis showed that cotton straw price, $\mathrm{Ca}(\mathrm{OH})_{2}$ price, $\mathrm{HCl}$ concentration, and days of operation were the key parameters influencing the price of levoglucosan production.

Financial analysis

Table 1. Financial analysis

\begin{tabular}{lcccccc}
\multicolumn{1}{c}{ Price conditions } & $\begin{array}{c}\text { Levoglucosan } \\
\text { price }(\mathbf{s} / \mathbf{k g})\end{array}$ & $\begin{array}{c}\text { GM } \\
(\%)\end{array}$ & $\begin{array}{l}\text { ROI } \\
(\%)\end{array}$ & $\begin{array}{l}\text { IRR } \\
(\%)\end{array}$ & $\begin{array}{c}\text { NPV } \\
\text { (million \$) }\end{array}$ & $\begin{array}{c}\text { PBT } \\
\text { (year) }\end{array}$ \\
\hline Factory in Henan, China & 3.5 & 5.1 & 14.0 & 13.1 & 14.8 & 7.1 \\
Factory in Shaanxi, China & 4.5 & 22.4 & 42.9 & 46.8 & 125.9 & 2.3 \\
120\% of production cost & 3.9 & 12.9 & 25.6 & 28.4 & 59.5 & 3.9 \\
150\% of production cost & 4.9 & 27.6 & 54.5 & 57.3 & 170.3 & 1.8 \\
Lowest price in Alibaba & 10.0 & 61.2 & 201.9 & 145.6 & 735.3 & 0.5 \\
Average price in Alibaba & 25.0 & 83.6 & 635.5 & 278.5 & $2,396.9$ & 0.2 \\
\hline${ }^{*}$ Minimum selling price & 3.6 & 7.2 & 16.9 & 17.3 & 26.2 & 5.9 \\
\hline
\end{tabular}

Changing the market price $(\$ / \mathrm{kg})$ from 3.5 to 4.9 increased the IRR from $17.3 \%$ to $57.3 \%$

For a project, involving a rather high-risk level, the suggested IRR is usually $15 \% 4$, so, to achieve a $15 \%$ IRR, the minimum

Tevoglucosan selling so, to achas $\$ 3.6$ alkg for hils system. 列

\section{CONCLUSIONS AND FUTURE WORKS}

- The levoglucosan production via fast pyrolysis and extraction of cotton straw has a high potential to be an attractive alternative

Future work should focuse on the utilization of levoglucosan and the life cycle assessment of levoglucosan production and

BIBLIOGRAPHY

1. Wang J et al. J. Anal. Appl. Pyrol. 2016

2. Helle S. et al. Carbohydr. Res. 2007

Zhang Y. et al. Blos. J. Wh. Technol. 2013

ind Eng. Ind. Aerod. 2006

5. Alibaba. https://www.alibaba.com/

ACKNOWLEDGEMENTS

China Scholarship council, OSU/OARDC/FABE, USDA-NIFA Hatch Project: 1005665 